\title{
ESTUDO DE FONTES E LEITURA IMANENTE: ALGUMAS CONSIDERAÇÕES METODOLÓGICAS A PARTIR DO CASO NIETZSCHE
}

\author{
Rogério Lopes \\ Universidade Federal de Minas Gerais
}

\begin{abstract}
In this paper, I argue that the method of intellectual contextualization (based on source criticism) is more appropriate for explaining much of Friedrich Nietzsche's work than the method of immanent reading. Whatever the merits and limitations of both methods, two main characteristics of Nietzsche's work turn the contextual approach into the most promising one: the nietzschean conception of the philosophical task (intimately connected with his perfectionism), insofar as it compels the philosopher to deal with abstract entities (such as propositions, arguments, concepts and metaphors) in a predominantly instrumental way; his preference for the aphorismatic way of writing, insofar as it compels him to suppress a significant part of his premises. The limits for the instrumental appropriation of philosophical arguments will be discussed in the last section of this paper.
\end{abstract}

Keywords: Nietzsche, source criticism, immanent reading, intellectual context.

Resumo: Este artigo oferece alguns argumentos a favor da tese de que o método de reconstrução do contexto intelectual (baseado no exame crítico das fontes) é mais adequado ao entendimento da obra de Nietzsche do que o método de leitura imanente. Independentemente dos méritos e limitações das respectivas metodologias, duas características gerais da obra de Nietzsche tornam a abordagem contextual mais promissora: a concepção nietzscheana da tarefa filosófica (derivada de seu compromisso com 0 perfeccionismo ético), na medida em que esta o leva a tratar de forma instrumental entidades abstratas (tais como teses, argumentos, conceitos e metáforas); e sua preferência pela forma de exposição aforismática, na medida em que esta o obriga a ocultar parte importante de suas premissas. O limite para a instrumentalização de argumentos filosóficos será examinado na última seção do artigo.

Palavras-chave: Nietzsche, estudo de fontes, leitura imanente, contexto intelectual. 


\section{I - Introdução}

Tornou-se quase um lugar comum nos comentários acerca da segunda Consideração Extemporânea a afirmação de que se trata de um livro sobre o qual pairam grandes dúvidas. A começar pela recepção imediata, pouco calorosa e por vezes reticente entre os amigos de Nietzsche, recepção esta que acabou por influenciar o juízo do próprio autor ${ }^{1}$. Thomas Brobjer, por exemplo, mostrou recentemente que, dentre todos os livros do Nietzsche, este é o que mereceu o menor número de referências e comentários de sua parte². Tudo isso parece sugerir que a segunda Extemporânea é uma obra malograda, cujas teses não teriam resistido às sucessivas e por vezes drásticas revisões a que Nietzsche submetia periodicamente sua filosofia. As considerações que farei a seguir sugerem, entretanto, que a revisão de uma tese ou o abandono de uma determinada estratégia argumentativa não deveria fornecer ao filósofo uma razão suficiente para manter distância ou guardar silêncio em relação a uma obra. A hipótese a ser investigada é a de que a relação que Nietzsche estabelece com suas teses e com os argumentos que as sustentam é uma relação que se pretende na medida do possível instrumental: a adesão a tais entidades abstratas, cujo bom manuseio caracteriza parte substantiva da atividade filosófica (de Nietzsche, inclusive), deveria ser uma adesão puramente circunstancial. Esta é uma primeira razão, embora não a única, pela qual Nietzsche pode ser descrito como um pensador estratégico, experimental e visceralmente antidogmático ${ }^{3}$. Teses são posições sempre

\footnotetext{
${ }^{1}$ Cf. a este respeito GERHARDT, 1988, p. 133 e SALAQUARDA, 1984.

2 BROBJER, 2004, p. 303: "Although On the Uses and Disadvantages of History for Life has received massive attention in the twentieth century, it received little attention and sympathy even from Nietzsche's friends and acquaintances, and was reviewed only once during the 1870s. Nietzsche himself seems to have had little or no interest in it after he had published it. There are good reasons to believe that Nietzsche regarded this work as his least valuable book. Nietzsche hardly ever refers to the second Untimely Meditation even when he mentions the other Untimely Meditations either in his books, letters or notebooks. The few times he refers to it, he seems mostly to deny its argument, content, and importance."

${ }^{3} \mathrm{~A}$ formulação mais bem acabada desta posição encontra-se no parágrafo 54 de 0 Anticristo, que eu cito apenas em parte: "Não nos deixemos induzir ao erro: grandes espíritos são céticos. Zaratustra é um cético. A firmeza, a liberdade que vem da força e sobreforça do espírito prova-se pela disposição cética (Skepsis) [...]. Um espírito que quer coisas grandes, que quer também os meios para elas, é necessariamente um cético. Ser livre de todo tipo de convicções faz parte da força, poder olhar livremente... A grande paixão, o fundamento e o poder de seu ser, ainda mais esclarecida, mais despótica do que ele mesmo, toma todo o seu intelecto a seu serviço; ela torna o espírito audacioso; dálhe coragem até para meios não santificados; sob certas circunstâncias ela permite a ele convicções. A
} 
provisórias que o filósofo ocupa, com o intuito de testar não apenas suas implicações lógicas, mas também históricas e psicológicas; ou seja, elas permitem montar certos experimentos de pensamento. Tais testes ou experimentos são realizados com o auxílio das ferramentas tradicionais da lógica, mas também e principalmente com o apoio de hipóteses sugeridas pelas ciências empíricas e com os recursos da imaginação poética. Argumentos são bons na medida em que suportam teses que por sua vez favorecem formas de vida que incorporam valores que Nietzsche deseja promover ou cultivar. Em especial, a forma de vida contemplativa encarnada em tipos de exceção que Nietzsche identifica com os filósofos, quase sempre com os filósofos do futuro, na forma de uma tarefa. Os argumentos são geralmente avaliados segundo o valor estratégico que têm na consecução desta tarefa. Isso pode parecer pouco digno de um filósofo, mas esta tese metafilosófica deve ser apreciada no contexto do compromisso nietzscheano com o perfeccionismo. Chamo a atenção para este aspecto, mas não tenho a intenção de examinar aqui as implicações deste compromisso, e tampouco a questão se estamos diante de uma posição defensável.

Mas mesmo se o nosso interesse aqui se restringe a examinar as implicações argumentativas de se investir parte substancial da energia filosófica na promoção de formas de vida excelentes, as dificuldades não são necessariamente menores, pois Nietzsche não se limitou a propor uma única imagem da vida filosófica ao longo de sua obra ${ }^{4}$. Se ele tivesse esboçado uma única e não, como é o caso, uma sucessão de imagens do tipo filosófico da vida contemplativa, então a tarefa de identificar a ocorrência e avaliar a relevância de certas teses e argumentos em sua obra teria sido imensamente simplificada. Tal limitação, entretanto, teria tornado o seu pensamento menos atraente e consideravelmente mais esquemático. Se esta descrição está correta, isso significa que o caráter experimental e a atitude antidogmática da filosofia de Nietzsche não se devem somente ao fato de ele aderir apenas circunstancialmente a certas teses, e de estabelecer uma relação antes de tudo instrumental com argumentos filosóficos. Gostaria de sugerir que há algo ainda mais decisivo em jogo, cujo exame permite apreender as dificuldades

convicção como meio: muita coisa se alcança apenas por meio de uma convicção. A grande paixão precisa, ela se serve de convicções, não se submete a elas - sabe-se soberana." (KSA, 6: p. 236).

4 Para uma apresentação detalhada das inúmeras imagens da vida contemplativa esboçadas por Nietzsche nas obras do período intermediário, cf. o belo estudo de BRUSOTTI, 1997. 
que se apresentam ao filósofo na medida em que ele se propõe de modo programático a se relacionar de forma apenas instrumental com teses e argumentos filosóficos. Isto a que me refiro como o ainda mais decisivo diz respeito aos compromissos vitais que caracterizam as diversas versões da vida contemplativa propostas por Nietzsche. Um exame destes compromissos vitais revela que há entre eles e certas teses e argumentos filosóficos laços de solidariedade que não podem ser suspensos pela mera habilidade dialética e/ou retórica de um autor. Estes laços de solidariedade impõem limites à apropriação de teses e argumentos filosóficos, restringindo a possibilidade de que eles favoreçam propósitos inteiramente alheios àqueles para os quais eles foram originalmente concebidos. Estamos diante de certas afinidades eletivas que conferem densidade histórica a tais entidades abstratas (teses, argumentos, conceitos), ao enraizá-las no solo de uma forma de vida. $\mathrm{Na}$ seção final deste artigo ilustro esta tese metafilosófica geral com um exemplo extraído de minha investigação recente acerca das fontes do ceticismo e dos usos de argumentos céticos por Nietzsche ${ }^{5}$. Naturalmente que é possível encontrar formas alternativas de argumentar a favor da plausibilidade da tese e que independem da correção dos resultados desta pesquisa; minha expectativa é que estes resultados forneçam uma corroboração indireta da tese, mas seria injusto exigir mais que isso da seção final deste artigo. Portanto, antes de ilustrar a tese, adoto outra estratégia e narro a experiência de pesquisa que me conduziu até ela, com o que finalmente tocamos no problema das fontes.

\section{II - Elucidação conceitual versus reconstrução das intenções argumentativas, ou das ilusões do imanentismo às agruras da linguagem natural.}

Há alguns anos atrás, ao redigir a última seção de meu estudo sobre a presença de elementos retóricos na obra de Nietzsche, me vi confrontado com um problema metodológico que provavelmente está na origem de minha atual convicção de que não é possível compreender satisfatoriamente as intenções argumentativas de Nietzsche sem uma identificação prévia das fontes com as quais ele está dialogando ou das quais ele está se apropriando de uma forma ou outra. Este problema surgiu no contexto de uma reflexão

${ }^{5}$ Cf. LOPES, 2008. 
mais ampla sobre as escolhas literárias de Nietzsche e os desafios interpretativos impostos por estas escolhas. Busquei me posicionar contra uma tese relativamente difundida na literatura secundária, segundo a qual a opção nietzscheana pela exposição aforismática excluía o regime argumentativo próprio à tradição filosófica. Minha objeção a esta tese começava pela adoção de uma compreensão alargada do que significam as noções de validação e invalidação quando aplicadas ao discurso filosófico, salientando a diferença entre demonstração, como um regime de prova que ocorre apenas em sistemas formais muito limitados, e argumentação, como o termo que designa uma ampla variedade de estratégias de convencimento e dissuasão em contextos diversos ${ }^{6}$. No caso específico de Nietzsche, havia ainda a necessidade de diferenciar entre o gênero puro do aforismo (que exclui o regime argumentativo e tem uma ocorrência apenas periférica em Nietzsche) e a forma literária mais recorrente no autor, e que propus caracterizar como uma forma híbrida entre ensaio e aforismo. Eu sugeria, além disso, que esta forma de apresentação dos argumentos filosóficos, extremamente condensada, incorporava algo da estrutura entimemática do silogismo retórico, na medida em que ao adotá-la o autor negligenciava a demonstração sem abdicar da argumentação, mas o fazia de um modo tal que algumas de suas premissas eram meramente aludidas ou simplesmente ocultadas ${ }^{7}$. Interpretada de forma caritativa, esta estratégia textual pode ser vista como um convite para que o leitor exerça sua autonomia e assuma por sua conta e risco a tarefa de dar prosseguimento à reflexão (esta é a alegação feita por Nietzsche nas ocasiões em que ele reflete sobre sua escrita aforismática: cf. KSA, 2: p. 161-162; KSA, 2: p. 432). Andreas Urs Sommer, em artigo sobre as utilidades e desvantagens do estudo crítico das fontes aplicado ao caso Nietzsche, publicado no Nietzsche-Studien de 2000, e ao qual teremos oportunidade de voltar, sugere a possibilidade de uma interpretação menos caritativa daquilo que descrevi como estratégia nietzscheana de implicitação. Eis o que diz o autor:

\footnotetext{
${ }^{6}$ A distinção entre demonstração e argumentação a que me refiro foi proposta pelo filósofo belga Chaim Perelman, que por sua vez se inspirou no modelo da retórica e da dialética antigas ao propor uma concepção anticartesiana e mais tolerante da prova filosófica como parte de um amplo projeto de retomada e reconstrução da retórica. Este modelo deveria se aplicar a uma diversidade de práticas discursivas, entre elas a filosofia. Cf. PERELMAN, 1997.

7 Cf. LOPES, 2006, capítulo IV, seção 2: Entre aforismo e ensaio: retórica como estratégia de apresentação, p. 198-220.
} 
Um intérprete benevolente dirá que a escrita filosófica de Nietzsche não fornece, por razões de economia literária, quase nenhuma informação sobre sua própria genealogia; enquanto um intérprete algo menos benevolente falará de uma estratégia deliberada de autocanonização mediante o obscurecimento das próprias origens ${ }^{8}$.

Uma leitura imanente dos textos filosóficos tem méritos inegáveis; ela é um pré-requisito de toda atividade de compreensão de textos e, na filosofia, ela tem ainda o mérito adicional de nos distanciar da ingênua suposição de que diferentes filósofos falam a mesma língua pelo simples fato de usarem as mesmas palavras, o que é uma forma singela de nos familiarizarmos com a existência de conceitos no sentido filosófico genuíno. A tentativa, contudo, de reivindicar exclusividade para tal método funda-se em suposições que não me parecem sustentáveis. Gostaria de destacar apenas uma delas; a da autonomia absoluta do texto face ao contexto. A recusa do contexto por parte dos defensores do método estrutural e imanentista foi feita com base no princípio, inteiramente saudável, da responsabilidade filosófica e com o objetivo, igualmente legítimo, de preservar o espaço lógico das razões, evitando a substituição da ordem das razões pela do encadeamento das causas (através de uma explicação sociológica ou psicologizante da gênese das doutrinas filosóficas), resguardando assim a especificidade do pensamento filosófico e sua autonomia. Esta motivação, ainda que excessivamente racionalista na sua justificativa, é legítima e não creio que o estudo de fontes recuse inteiramente esta aspiração. Para tanto devemos esclarecer que o método de exame crítico das fontes entende 'contexto' no sentido de contexto intelectual, e não no sentido de contexto socioeconômico ou político. O que a pesquisa de fontes contesta é a autonomia absoluta das ideias e o isolamento do pensador no interior de seu sistema: o que há efetivamente é um pensador lutando contra as resistências que seu material lhe oferece (a linguagem natural e os diversos estratos de significação que nela se sedimentaram ao longo de um processo de sucessivas apropriações ou interpretações), na tentativa de pensar algo novo e de agir sobre o seu tempo.

${ }^{8}$ SOMMER, 2000, p. 313: "Als wohlwollender Interpret wird man sagen, Nietzsches philosophisches Schreiben gebe aus Gründen der schriftstellerischen Ökonomie kaum Auskunft über seine eigene Genealogie, während man als etwas weniger wohlwollender Interpret von einer gezielten Strategie der Selbstkanonisierung durch Verunklarung der eigenen Ursprünge sprechen wird". 
Devemos notar que a necessidade de um estudo das fontes se impõe apenas para aqueles intérpretes que entendem o seu trabalho como um trabalho historiográfico, comprometido com a reconstrução do contexto intelectual do autor como uma precondição para a formulação de juízos de intencionalidade. Em um debate entre estudiosos de Nietzsche é desnecessário dizer que esta é apenas uma das tantas perspectivas possíveis a partir da qual podemos nos aproximar de nosso objeto de trabalho. Mas uma vez adotada esta perspectiva, o objetivo último da pesquisa historiográfica é responder não tanto a perguntas do tipo: o que Nietzsche entendeu pelo conceito tal ou qual, mas a perguntas do tipo: o que Nietzsche pretendeu ao utilizar o conceito tal e qual no contexto $x$ ou $y$. A primeira tarefa, de elucidação conceitual, passa a estar subordinada à segunda, de compreensão do funcionamento dos argumentos quando reinseridos no contexto mais amplo de disputas que define o horizonte intelectual de uma época; somente este recuo ao contexto permite arriscar juízos de intenção que são necessários para compreender o uso efetivo de um argumento por um autor. Este procedimento é muito distinto do procedimento de isolar um argumento e convertê-lo em uma entidade abstrata, cuja validade pode ser determinada independentemente da densidade histórica que envolve o argumento e que confere a ele o estatuto de um acontecimento ou, para sermos mais precisos, o estatuto de uma ação, ainda que da ordem do pensamento. Creio que o primeiro procedimento é fiel em sua inspiração àquilo que Nietzsche tinha em mente ao propor um critério perspectivístico para a avaliação dos juízos. O foco não é tanto sobre a elucidação de conceitos, mas sobre os usos a que tais conceitos são submetidos em determinados contextos argumentativos. Elucidamos os sentidos de um conceito mediante definições; identificamos os usos quando somos capazes de atribuir juízos de intenção a um autor e de fundamentar esta atribuição; é o próprio Nietzsche que nos adverte (na segunda Dissertação da Genealogia, §13) que os sentidos dos conceitos são fluidos justamente porque eles são continuamente submetidos a novos usos, a novas interpretações: "Todos os conceitos nos quais um processo inteiro é semioticamente abreviado escapam à definição; definível é apenas aquilo que não tem história” (KSA, 5: p. 317). A estabilidade e univocidade dos conceitos são aparentes e induzidas, na maior parte das vezes, pela unidade da palavra, que se aproveita da pouca cautela dos filósofos e de sua falta de sentido histórico. Um exemplo do que tenho em mente com este contraste entre duas abordagens, uma que privilegia a elucidação conceitual e outra que 
se concentra na reconstrução das intenções do autor: é de fundamental importância compreender conceitualmente o princípio da vontade de poder; mas é ainda mais fundamental chegarmos a um entendimento das motivações que levaram Nietzsche a sugerir a 'vontade de poder' como um princípio interpretativo. Creio que não é possível solucionar esta última questão sem a reconstrução do contexto intelectual do filósofo.

Ao invés de uma história das ideias (centrada na elucidação de entidades abstratas em um espaço lógico e atemporal das razões), o que teríamos então seria uma história de movimentos efetivos de argumentação, cujo significado só pode ser apreendido mediante a reconstrução do contexto linguístico no interior do qual eles foram realizados e se inseriram polemicamente ${ }^{9}$. A suposição de uma autonomia absoluta das ideias é incompatível com o que sabemos hoje, mais no do nunca, acerca do funcionamento das linguagens naturais. O cenário ideal no qual o método de leitura imanente poderia reivindicar exclusividade seria um no qual o intérprete estivesse diante de um texto capaz de instaurar, de forma exaustiva, suas próprias regras de inteligibilidade e de comunicá-las de forma unívoca, sem que no intervalo entre uma coisa e outra, ou seja, no intervalo entre a produção e a recepção do texto, houvesse a interferência dos ruídos da história, que tornam ainda menos transparentes as já pouco transparentes regras convencionais da linguagem (sintáticas, semânticas e pragmáticas) que governam o fenômeno da compreensão. Mas supor que tal façanha seja exequível no terreno movediço das convenções de sentido e de uso que caracterizam as linguagens naturais (o único terreno possível para a filosofia) é o mesmo que atribuir a um autor o controle absoluto dos signos linguísticos e das regras de combinação destes signos. Se esta redução ao absurdo da tese da exclusividade está correta, então o que temos é a surpreendente constatação de que na perspectiva do método de leitura imanente o texto é compreendido como um sistema formal axiomaticamente definido. Apenas sistemas formais de alcance muito limitado comportam um processo mecânico de decisão, pois estes se reduzem a um vocabulário previamente especificado de signos artificiais, regras de combinação dos signos que são exaustivas, e regras tautológicas de derivação. Têm um caráter impessoal e todos os seus teoremas, caso não haja erro na aplicação das regras, são logicamente necessários, ou seja, constrangem à adesão. A utopia

\footnotetext{
${ }_{9}^{9}$ Para uma discussão mais detalhada deste ponto, conferir SKINNER, 1988: p. 29-67.
} 
de criar uma linguagem com tais características para a filosofia naufragou na primeira metade do século XX, como todos sabem.

A redução ao absurdo do método de leitura imanentista esboçado acima se aplica apenas à pretensão de exclusividade. Ainda assim, ela é excessivamente caricatural e não faz justiça à intenção, e muito menos aos resultados obtidos por seus adeptos e praticantes. Contudo, mesmo em uma versão moderada, este método não me parece ser o método mais rentável para tratar de um autor que oculta sistematicamente suas premissas e se recusa a oferecer uma exposição sistemática de suas teses. Esta preocupação veio à tona nas linhas finais da última seção do referido estudo nos seguintes termos, que tomo a liberdade de citar:

Ao ocultar o contexto argumentativo que está na origem de sua própria reflexão, ou ao referir-se a este contexto de forma apenas alusiva, Nietzsche pode somente indicar, mas não tornar explícita a complexa rede de debates na qual ele está envolvido, assim como a extensão de seu débito com a tradição e com sua própria época. Este contexto pode ser cuidadosamente refeito por estudos eruditos que se debrucem sobre os textos póstumos e a biblioteca pessoal do filósofo, ou por uma leitura igualmente minuciosa das indicações que estão como que nas entrelinhas de seus escritos, mas certamente escapa ao leitor ocasional de Nietzsche, que deste modo se torna presa fácil das suas inúmeras armadilhas. (LOPES, 2006, p. 214).

Ao tentar reconstruir o diálogo de Nietzsche com a tradição cética, tema de minha Tese de doutoramento, procurei seguir a primeira sugestão metodológica, ou seja, me debruçar sobre a biblioteca ideal e real de Nietzsche, sua correspondência e seus fragmentos póstumos, motivado pela desconfiança de que por mais arguto que seja um leitor, ele não conseguirá reconstruir adequadamente as intenções argumentativas de um autor atendose apenas às indicações que se encontram nas entrelinhas de seus escritos.

\section{III - 0 exame crítico das fontes: com qual intuito?}

O estudo de fontes não é certamente a única via para colocar Nietzsche em diálogo com a tradição filosófica. Um estudo comparativo pode fazê-lo igualmente bem, a depender do vigor daquele que move as peças 
no tabuleiro das ideias. Mas na perspectiva de um estudo comparativo este diálogo terá necessariamente que ocorrer no espaço rarefeito das razões, e não no palco tumultuado da história efetiva (que envolve encontros casuais, idas e vindas, avanços e recuos, incompreensões e vias tortas, protagonistas brilhantes e atores medíocres). Mas se queremos nos livrar de uma vez por todas da crença, pouco produtiva em minha opinião, de que a filosofia é um monólogo de seres de exceção em torno de questões atemporais, então creio que não há outra via senão a do exame atento das fontes ${ }^{10}$. Esta via é certamente a mais árdua, mas nada garante que ela seja a mais criativa e rica do ponto de vista dos resultados. Além disso, como toda via erudita, ela corre o risco de ater-se a detalhes irrelevantes e descambar no pedantismo. No entanto, ela é a única via possível para desfazer alguns dogmas em torno de Nietzsche e em torno do que significa fazer história da filosofia. Eu menciono dois deles. O primeiro é a tese, que já gozou de alguma reputação, segundo a qual Nietzsche não estava familiarizado com a tradição filosófica e que seu conhecimento dos clássicos se resumia a Platão e Schopenhauer. Como bons nietzscheanos, treinados na escola da suspeita, devemos nos perguntar se o apego a esta convicção não oculta o secreto desejo de reservar a Nietzsche um lugar único na história da filosofia e aplicar à sua obra o monstruoso conceito de causa sui, espécie de aberração e perversidade lógica da qual não conseguimos nos livrar tão facilmente. Se queremos entender a nossa pesquisa sobre Nietzsche como parte de uma história edificante e monumental, e a sua obra como um conjunto de efeitos sem causa suficiente, então todo esforço de restituir Nietzsche à sua própria época será

\footnotetext{
${ }^{10}$ Esta compreensão monumental da história da filosofia, entendida como o desafio de converter em diálogo o que originalmente foi uma sequência de monólogos protagonizados por indivíduos de exceção, é abertamente defendida por Leo Strauss como o desdobramento natural de sua convicção de que os grandes filósofos do passado desenvolveram um modo peculiar de retórica filosófica, a escrita nas entrelinhas, que teria o objetivo tanto de evitar a censura quanto de proteger a cidade do efeito corrosivo das verdades filosóficas, garantindo deste modo a continuidade da própria filosofia. Através da escrita nas entrelinhas os grandes filósofos teriam sido capazes de transmitir seu ensinamento esotérico sobre as questões perenes da filosofia para um auditório de elite. (Cf. STRAUSS, 1988, Persecution and the Art of Writing). A imagem do filósofo que emerge desta compreensão da história da filosofia é pouco realista na medida em que ignora a resistência que a linguagem oferece para o pensamento. Para que 0 dispositivo do esoterismo pudesse ser bem-sucedido no sentido exigido por Strauss tanto o filósofo quanto 0 seu leitor ideal teriam que ter um domínio das convenções lingüísticas e de suas regras que não é factível atribuir a simples mortais. Uma imagem inteiramente distinta e mais realista do esoterismo filosófico emerge das páginas de Além de bem e mal. Infelizmente não posso desenvolver aqui este contraste, mas basta dizer que dela resulta uma visão bem mais modesta do sucesso da retórica filosófica.
} 
interpretado como uma tentativa de despotencializar sua filosofia e intimidar aqueles que pretendem se servir do filósofo para pensar por conta própria. Para estes nada mais resta a recomendar senão que reflitam sobre as considerações de Nietzsche acerca dos riscos contidos no olhar exclusivamente monumental sobre o passado ${ }^{11}$.

O segundo dogma aplica-se a Nietzsche e à história da filosofia como um todo: trata-se da crença de que as leituras mais decisivas realizadas por um grande filósofo são necessariamente as leituras daqueles autores que compõem o nosso cânone atual. Esta crença ignora o fato básico de que um autor geralmente responde aos seus contemporâneos. Por mais extemporâneo que um filósofo se pretenda, e Nietzsche certamente reivindicou esta condição com mais veemência do que qualquer outro grande filósofo da tradição, sua visão dos grandes filósofos e dos grandes problemas é mediada por uma série de autores que estarão, poucas décadas depois, relegados ao esquecimento. Menciono apenas alguns destes contemporâneos, cujas obras forneceram a Nietzsche um número significativo de teses e argumentos que um leitor não avisado inevitavelmente buscará na história da filosofia na sua versão mais canônica: Friedrich Albert Lange; Afrikan Spir, Eugen Dühring; Eduard von Hartmann; Otto Liebmann; Gustav Teichmüller e Maximiliam Drossbach. Nesta medida, o estudo de fontes se mostra mais uma vez como um poderoso e salutar corretivo para uma compreensão excessivamente monumental da história das ideias.

Para os que não têm simpatia por uma abordagem contextual dos textos filosóficos, há sempre à mão o argumento de que eles estão interessados nos problemas, na relevância e na atualidade filosófica das soluções propostas por um autor. Mas o intérprete com pendor historiográfico não precisa se sentir acuado por este tipo de alegação. $\mathrm{Na}$ verdade, ela pode fortalecer a sua própria posição, pois é pouco plausível que sejamos capazes de equacionar devidamente os termos de um problema (mesmo que ele seja de natureza filosófica) sem previamente recompormos a sua genealogia (como nos ensina Nietzsche). Os problemas, mesmo os problemas filosóficos, ganham os seus contornos, a sua urgência e a sua

\footnotetext{
11 Nietzsche identifica dois tipos de perigo na consideração exclusivamente monumental da história, conforme esta consideração esteja a serviço dos homens poderosos e ativos ou a serviço de homens fracos e indolentes; no primeiro caso ela produzirá homens temerários e fanáticos; no segundo caso ela produzirá um cânone que terá um efeito paralisante sobre as novas gerações, pervertendo assim 0 sentido da história monumental (Cf. KSA, 1: p. 262-263).
} 
dramaticidade somente quando restituídos ao contexto no qual eles foram elaborados. O filósofo está inserido neste contexto e ele escolhe seus argumentos levando em consideração, pelo menos em parte, aquilo que melhor responde a interlocutores e oponentes nomeados e não nomeados. Esta característica de não nomear interlocutores e oponentes se impõe com maior força no caso de autores como Nietzsche, que optou pela forma aforismática de apresentação dos argumentos.

Andreas Urs Sommer chega a conclusões bastante parecidas às que eu expus até o momento ao se perguntar pelo tipo de utilidade que um estudo crítico das fontes pode ter para o entendimento da filosofia de Nietzsche. Contudo, como eu havia mencionado acima, ele não parece muito disposto a adotar a versão mais caritativa acerca das razões que levaram Nietzsche a ocultar sistematicamente suas fontes. Segundo a minha interpretação, que aos ouvidos de Sommer soaria excessivamente complacente, esta é uma exigência que decorre da própria opção de Nietzsche pela forma aforismática de apresentação dos argumentos; a adoção desta estratégia de apresentação dos argumentos funda-se, por sua vez, em razões filosóficas absolutamente defensáveis ${ }^{12}$. Andreas Urs Sommer sugere que estamos diante de uma estratégia deliberada de autocanonização, que encena a sua própria originalidade e excepcionalidade com o intuito de se inscrever em uma história monumental ao lado dos grandes heróis e gênios da história universal. Nesta perspectiva, a utilidade do programa de uma investigação crítica das fontes de Nietzsche, tal como idealizado por Montinari como extensão do projeto de edição crítica das obras e da correspondência, programa que está ainda em execução, não se limita apenas a restituir a obra do filósofo ao seu contexto de surgimento; ao fazê-lo, este tipo de investigação produz no intérprete um efeito de distanciamento, e isso é uma decorrência necessária de remeter o texto ao seu contexto de surgimento e produção. Se por um lado a investigação crítica das fontes enfatiza a distância em

\footnotetext{
12 Cf. LOPES, 2006, p. 198-220. Uma belíssima defesa desta estratégia de exposição encontra-se no aforismo 178 do primeiro volume de Humano, demasiado Humano, intitulado A eficácia da incompletude: "Assim como as figuras em relevo agem tão fortemente sobre a imaginação por estarem como que em vias de saltar da parede e, subitamente, impedidas por não se sabe o quê, permanecerem imobilizadas, do mesmo modo a apresentação [Darstellung] incompleta, como que em relevo, de um pensamento, de toda uma filosofia, é mais eficaz do que a exposição exaustiva [Ausführung]; uma maior parte do trabalho é deixada ao encargo do espectador, que assim é estimulado a prosseguir na elaboração daquilo que se the sobressai com tal intensidade de luzes e sombras, a pensar até o fim e a superar por si mesmo os obstáculos que até então impediam o seu completo evidenciar-se." (KSA, 2, p. 161-162; cf. ainda KSA, 2, p. 432).
} 
detrimento do pathos, por outro lado ela segue uma tendência radicalmente igualizadora, em franca oposição à tendência canonizante de outras abordagens da história da filosofia e do próprio Nietzsche (cf. SOMMER, 2000: p. 311). Isso significa dizer que o programa de um exame crítico das fontes utilizadas por Nietzsche se contrapõe ao próprio filósofo por uma razão muito precisa e em um ponto essencial: não é tanto por se recusar a levar a sério sua retórica monumentalizante, ou por se manter indiferente à fascinação que as grandes doutrinas exerceram sobre os seus intérpretes clássicos, mas, sobretudo, por resistir às suas estratégias de apagamento dos vestígios, ou seja, de ocultamento das fontes. Sommer quase chega a censurar Nietzsche moralmente por não nos informar sobre suas leituras através de notas de rodapé, uma prática que, afinal de contas, já havia sido incorporada ao meio acadêmico alemão pela geração do historiador Leopold Ranke, geração que antecedeu à de Nietzsche (Cf. SOMMER, 2000: p. 313).

À primeira vista, foram algumas poucas reflexões de Nietzsche acerca da utilidade de uma investigação desta natureza que serviram de pretexto para o diagnóstico de Sommer de uma forte oposição entre a orientação básica da pesquisa de fontes, tal como formulada e praticada por Montinari e sua equipe, assim como por seus seguidores, e a compreensão que Nietzsche tinha de si mesmo e da própria história da filosofia (ambas marcadas pela mesma tendência canonizante e monumentalizante). Estas reflexões encontram-se publicadas no volume V da edição de Karl Schlechta, e foram concebidas originalmente à guisa de prefácio para uma de suas publicações sobre as fontes de Diógenes Laércio. Eu cito apenas parcialmente estas considerações do jovem filólogo:

É escassa a chance de darmos uma resposta precisa à pergunta 'quais livros um autor utilizou?' quando o autor em questão é superior aos escritores que lhe serviram de fonte, pois ele se utiliza destas fontes a seu bel-prazer e com inteira liberdade, vertendo em nova forma tudo aquilo que ele tomou delas a título de material e imprimindo em tudo o selo de sua personalidade. (BAW, vol. 5: p. 126)

Muitos historiadores superam a individualidade de suas fontes e <...> sem resto e anulam assim o pretexto necessário para toda pesquisa deste tipo; em outros casos, eles são desonestos ou preferem não ser controlados, e por estas razões 
eles ocultam deliberadamente o uso de suas fontes com um véu levemente tecido. Em outros casos, a honestidade de um historiador de nada nos serve, pois a fonte tantas vezes confessada não passa para nós, afinal de contas, de um nome envolto por uma espessa treva. Pois que tipo de questão nós estamos formulando em geral quando nos indagamos acerca das fontes de um autor? Um livro só pode se tornar mais compreensível para nós em sua forma, em seu conteúdo de pensamento, na medida em que temos a perspectiva de trocar não um nome por outro, mas conhecimento por conhecimento; nós queremos ver mais do que o livro pronto, nós queremos ter diante dos olhos a gênese de um livro, a história de sua gestação e nascimento: ocorre, além disso, que nos interessam mais os pais do que o filho, mais as fontes do que aquele que as trabalhou. Nós desejamos que o processo de seu vir a ser se revele lentamente diante de nosso olhar. (BAW, vol. 5: p. 126: itálico meu)

Embora Sommer tenha lá suas razões tanto para excluir outras motivações para a pesquisa de fontes quanto para insistir neste efeito igualizador como o principal efeito visado por este tipo de estratégia metodológica, é bem verdade que ambos os gestos podem ser sintomaticamente interpretados como frutos de sua incapacidade de se libertar da suspeita de que Nietzsche jamais abandonou a conviç̧ão de que só é possível resolver o problema da normatividade mediante o apelo a uma origem mítica (portanto, mediante o ocultamento da verdadeira origem). Mas a atribuição de tal convicção a Nietzsche não me parece justa ou bem fundamentada sequer para a sua obra de juventude. Mesmo em relação a $O$ Nascimento da Tragédia, a reivindicação de uma experiência privilegiada no contexto do gênero trágico é formulada por Nietzsche a partir de uma narrativa em que o evento estética e metafisicamente normativo é o resultado de uma combinação de elementos de diversas procedências. A tragédia grega é o resultado de uma história dinâmica da literatura grega, o seu ponto culminante, não algo dado na origem, derivado da essência do ser helênico ou da vontade grega. Parte importante da força normativa que Nietzsche reivindica para a antiguidade grega se deve ao modo exemplar com que, segundo o filósofo, os gregos teriam se apoderado e assimilado os diversos elementos com que se confrontaram ao longo de seu processo de formação, não raro de forma casual. Nietzsche recusa toda e qualquer versão do mito da 
autoctonia como chave de interpretação da cultura grega e como argumento a favor da normatividade da antiguidade clássica. A tese de Andreas Urs Sommer (outra versão da mesma tese sustenta a leitura que Paul de Man faz de O Nascimento da Tragédia ${ }^{13}$ ) está em fragrante contradição com o que Nietzsche diz nas considerações iniciais que abrem o seu ensaio póstumo sobre a filosofia na época trágica dos gregos. Contrariamente ao que supõe Andreas Urs Sommer, não precisamos aguardar a publicação de Humano, demasiado Humano para vermos Nietzsche se distanciar de sua concepção da normatividade como algo referido a e sustentado pelo vigor da origem. Há uma razão muito simples de porque não precisamos fazê-lo: é que Nietzsche em momento algum adotou tal estratégia para resolver o problema da normatividade. A exemplaridade dos gregos não se encontra na essência da alma grega, mas naquilo que eles foram capazes de fazer de si mesmos a partir da assimilação dos mais díspares elementos tomados do oriente:

Nada é mais tolo do que atribuir aos gregos uma cultura autóctone: pelo contrário, eles sorveram toda a cultura viva de outros povos e, se foram tão longe, é precisamente porque sabiam retomar a lança onde um outro povo a abandonou, para arremessá-la mais longe. São admiráveis na arte do aprendizado fecundo, e assim como eles devemos aprender de nossos vizinhos, usando o aprendizado para a vida, não para o conhecimento erudito, como esteios sobre os quais lançar-se mais alto, e mais alto do que o vizinho (NIETZSCHE, 1983: p. 32; KSA, 1: p. 806).

De resto, é preciso dizer que um exame crítico das fontes não está necessariamente a serviço da tendência radicalmente igualizadora reivindicada por Sommer. Ela certamente visa a combater os efeitos nocivos de uma consideração exclusivamente monumental da história. Mas o seu resultado pode ser o de expor, com a sobriedade científica que a caracteriza, o modo como um autor é admirável na arte do aprendizado fecundo, na medida em que é capaz de se apropriar de forma criativa de tudo aquilo que a tradição e o acaso de sua própria época lhe oferecem como estímulos para a sua reflexão. $\mathrm{O}$ exame crítico das fontes não deve, contudo, se restringir aos

${ }^{13}$ Cf. DE MAN, 1996. 
casos em que este trabalho de apropriação é bem-sucedido. Pode ser instrutivo em igual ou maior medida compreender o modo como um pensador, em seu diálogo com a tradição e com sua própria época, procurou administrar tensões e resistências. Fornecer as condições para o correto diagnóstico destas tensões e resistências é um dos grandes méritos de um exame crítico das fontes. $\mathrm{O}$ reconhecimento destas tensões e resistências tampouco implica demérito para o filósofo, mesmo quando ele não tenha sido capaz de superá-las. Portanto, também sob este prisma não há nenhuma boa razão para supormos que a estratégia de contextualização atende necessariamente a uma motivação radicalmente igualizadora, como pretende Sommer. A pesquisa de fontes exige o exercício da suspeita (muitas vezes dirigida ao próprio autor cujas fontes estão sendo examinadas), mas a escola da suspeita não é necessariamente uma escola da difamação. Em algumas circunstâncias ela pode nos ensinar o sentido de uma nova reverência.

\section{IV - Breve ilustração da tese: a constatação dos limites para a instrumentalização de argumentos céticos pelo jovem Nietzsche.}

Para encerrar, retomo o tema do ceticismo para ilustrar a minha tese inicial. Em contraste com a suspeita de Sommer, segundo a qual Nietzsche instrumentaliza suas fontes (por não restituí-las devidamente, ao que tudo indica), eu me limito a defender a tese de que Nietzsche se relaciona de forma instrumental com teses, argumentos, conceitos, metáforas e todos os demais tipos de entidades abstratas que pertençam ao campo das convenções de sentido (é um erro recorrente entre alguns intérpretes de Nietzsche a suposição de que metáforas, e demais construções semanticamente desviantes, escapam às convenções de sentido e franqueiam um espaço de maior liberdade para o pensamento, como se elas pairassem acima das estruturas gramaticais para cuja sedução o filósofo nos alerta com frequência) e que podem ser postas a serviço da promoção de certas formas de vida (independentemente da proveniência de tais entidades abstratas, se próprias ou alheias, de contemporâneos ou de homens do passado). Mas como vimos anteriormente, estas entidades abstratas guardam certos laços de solidariedade com o solo do qual elas brotaram. Esta é a razão pela qual Nietzsche se interessa menos pelo exame da solidez de determinados argumentos tomados isoladamente do que pela investigação de suas ressonâncias e implicações históricas e psicológicas. É o resultado desta investigação que permitirá a ele 
avaliar em que medida determinados modelos argumentativos disponíveis na tradição podem ser postos a serviço de uma nova intenção filosófica. Deste ponto de vista, argumentar filosoficamente significa arriscar a inserção polêmica no interior de uma tradição com vistas à produção de certos efeitos, digamos, persuasivos, mas com a convicção prévia de que tais efeitos jamais podem ser inteiramente controlados; seja porque o filósofo não domina inteiramente a tradição, seja porque a ele é impossível determinar o destino de sua própria recepção (e não há como negar que justamente uma tal ilusão está na origem da excessiva valorização do método de leitura imanentista). Uma das questões mais difíceis da historiografia filosófica talvez seja precisamente a de determinar o grau e a natureza da solidariedade que se estabelece entre determinados argumentos e as formas de vida no interior das quais e para cuja promoção eles foram gerados. Este é um problema que certamente se coloca para o historiador da filosofia; mas ele se coloca igualmente, e talvez com uma urgência ainda maior, para o filósofo que quer intervir ativamente nas disputas culturais de sua época e arriscar sua inserção na tradição. Quanto maior o grau de solidariedade entre um argumento e uma forma de vida, tanto mais difícil será deslocá-lo para um novo contexto histórico e colocá-lo a serviço de uma nova intenção filosófica. Creio, entretanto, que embora não seja ilimitada, a margem de manobra tende a ser grande, e que argumentos filosóficos se deixam instrumentalizar com alguma facilidade. Mas eles arrastam consigo algo do solo original do qual eles foram transplantados e podem muitas vezes escapar ao controle daqueles que supostamente os instrumentalizam. Esta solidariedade é o que confere densidade histórica aos argumentos e conceitos filosóficos e nos obriga a sermos apenas moderadamente nominalistas no trato com tais entidades abstratas. A atitude do jovem Nietzsche em relação a argumentos céticos ${ }^{14}$ ilustra de forma bastante satisfatória o sentido das reflexões metodológicas que desenvolvi até o momento.

Do ponto de vista da tarefa que Nietzsche se propôs no início da década de 70 argumentos céticos funcionam como um vigoroso aliado, o que torna evidente que o principal obstáculo à execução do programa de uma metafísica de artista não está na aceitação da correção epistêmica do ceticismo. Pelo contrário, esta é uma premissa essencial do próprio programa,

${ }^{14}$ Para uma investigação detalhada da recepção da tradição cética na filosofia de Nietzsche, cf. LOPES, 2008. 
uma premissa cuja verdade Nietzsche considera ter sido estabelecida historicamente por seus precursores. A tarefa que Nietzsche se propôs neste período para a sua filosofia pode ser traduzida nos seguintes termos: determinar as condições sob as quais uma cultura como unidade de diferentes impulsos pode ser pensada e se torna possível. Segundo o seu diagnóstico, nenhuma cultura moderna pôde satisfazer plenamente estas condições em função da hipertrofia de seu impulso cognitivo. Portanto, caberia à filosofia a tarefa de disciplinar o impulso cognitivo da modernidade, mas para tanto seria necessário à filosofia se desincumbir da tarefa prévia de compreender como esta hipertrofia se tornou possível. Nietzsche identifica na vitória da tendência socrática, que significou a imposição do otimismo teórico sobre a visão trágica de mundo na Grécia clássica, a raiz mais remota deste desequilíbrio dos impulsos no interior da cultura moderna. A tendência socrática ofereceu uma justificativa metafísica para a atividade teórica ao pressupor um acesso cognitivo à essência das coisas e equacionar conhecimento, virtude e felicidade. $\mathrm{O}$ imenso progresso das ciências na modernidade deve ser interpretado, sob esta ótica, como um efeito tardio da reviravolta socrática. Os pressupostos metafísicos que asseguram legitimidade à forma de vida incorporada na atividade científica são ainda hoje os pressupostos socráticos. Neste contexto podemos entender a função de argumentos céticos. Eles permitem desmontar a premissa socrática da cognoscibilidade do mundo. Nietzsche pretende retomar aqui um modelo argumentativo que ele supõe ter encontrado pela primeira vez em Kant: ao limitar nosso conhecimento às verdades empíricas das ciências, argumentos céticos apontam para a necessidade de rever o significado metafísico que a tradição ocidental teria supostamente atribuído à atividade teórica desde a vitória da tendência socrática. Nesta medida argumentos céticos abrem espaço para uma visão de mundo na qual a atividade teórica está subordinada a outros domínios da experiência. Nietzsche parece vislumbrar dois domínios da experiência aos quais seria possível conferir um significado metafísico, uma vez esgotada a força civilizacional do otimismo teórico de inspiração socrática: a atividade moral e a atividade estética. A primeira alternativa foi adotada por Kant; a segunda teria sido a via sugerida por Schopenhauer. Devemos notar ainda que o predicado "metafísico" qualifica antes de tudo tipos específicos de atividade humana, e só indiretamente conjuntos de crenças. Atribuir um significado metafísico a um tipo de atividade humana em detrimento de outras consiste em determinar 
uma hierarquia de formas de vida no interior da cultura. $\mathrm{O}$ esforço por promover metafisicamente a experiência estética é um indício da disposição de Nietzsche para, neste momento de sua obra, atribuir um papel secundário à forma de vida filosófica no interior de sua metafísica da cultura.

À primeira vista não há maiores dificuldades envolvidas no primeiro movimento desta estratégia argumentativa. Argumentos céticos realmente podem ser mobilizados para este propósito negativo, e esta parece ter sido de fato a intenção de Kant ao recorrer a argumentos pirrônicos, como parte de um uso defensivo da razão pura para resguardar seu interesse prático nas ideias da razão ou nos objetos das ditas proposições transcendentais. A dificuldade surge no passo seguinte. Argumentos céticos permitem contestar a pretensão de certas formas de vida, mas não têm nada a dizer em favor de candidatos concorrentes, exceto se for o caso de uma forma de vida ela mesma cética. Este é o limite imposto para a instrumentalização de argumentos céticos: se não se quer adotar a forma de vida cética para cuja promoção eles foram originalmente concebidos, então é necessário se contentar com sua contrapartida negativa. Aqui há ainda um notável fator agravante: associando a suspensão do juízo a uma espécie de imperativo da consciência intelectual em situações de indecidibilidade epistêmica, Nietzsche retira o ceticismo da posição de um espectador neutro em relação às pretensões edificantes dos diversos sistemas metafísicos e o converte em um adversário de todos eles. Isto ocorre porque ao fazer esta associação Nietzsche se compromete implicitamente com um aspecto essencial do ceticismo como forma de vida: seu esforço por preservar a integridade intelectual. Para entender o que Nietzsche designa no início da década de 70 por conhecimento trágico, em contraposição à visão de mundo do otimismo teórico, basta lembrar que ele considera que a tarefa do filósofo é antes de tudo a promoção da cultura, e que para tanto é imprescindível uma justificação metafísica da existência, pois somente ela evita que a "vontade" se precipite no abismo do pessimismo prático. Em outros termos, o engajamento na cultura exige um consolo de natureza metafísica, sendo incompatível com a suspensão do juízo exigida pelo imperativo da consciência intelectual. As exigências da cultura e da vida em geral parecem contradizer as exigências da consciência intelectual. Como a cultura designa a totalidade dos impulsos humanos e o modo de sua harmonização, as exigências da consciência intelectual devem vir em segundo plano. Mas Nietzsche não está plenamente convencido da legitimidade desta subordinação, de modo que a tensão atravessa toda a primeira fase de sua obra 
e, em alguma medida, prossegue ao longo de toda a sua vida produtiva, encontrando apenas pequenos intervalos nos quais uma plena reconciliação é vislumbrada. O que está em jogo é uma dupla exigência que Nietzsche coloca para a vida filosófica: a promoção da excelência humana e a atenção às normas da honestidade intelectual. Harmonizar estas duas tendências é sua grande ambição. A tensão relaciona-se apenas indiretamente ao ceticismo epistemológico. Podemos filiar esta dupla exigência a dois personagens conceituais que frequentam de forma obsessiva a reflexão filosófica de Nietzsche: Platão e Sócrates. Fixar as condições optimais sob as quais determinados indivíduos excepcionais podem entregar-se ao exercício da superação de si é a tarefa que Nietzsche associa à filosofia tal como Platão a teria secretamente compreendido e praticado. Este é o sentido mais preciso de seu propalado platonismo político. Não poder subtrair-se às exigências da veracidade é a marca mais visível de que Nietzsche, talvez em um grau mais intenso do que Platão, foi corrompido por Sócrates, o supremo mestre do erotismo.

\section{Referências bibliográficas}

BRUSOTTI, M. Die Leidenschaft der Erkenntnis. Philosophie und ästhetische Lebensgestaltung bei Nietzsche von Morgenröthe bis Also Sprach Zaratustra. Berlin: de Gruyter, 1997.

BROBJER, T. "Nietzsche's View of the Value of Historical Studies and Methods". In: Journal of the History of Ideas, 65, 2004: p. 301-322.

DE MAN, P. Alegorias da leitura: linguagem figurativa em Rousseau, Nietzsche, Rilke e Proust. Trad. Lenita R. Esteves. Rio de Janeiro: Imago, 1996.

GERHARDT, V. "Leben und Geschichte: Menschliches Handeln und historischer Sinn in Nietzsches zweiter „Unzeitgemäßer Betrachtung “"”. In: Pathos und Distanz: Studien zur Philosophie Friedrich Nietzsches. Stuttgart: Reclam, 1988, p. 133-162.

LOPES, R. A. Elementos de Retórica em Nietzsche. São Paulo: Loyola, 2006. . Ceticismo e vida contemplativa em Nietzsche. Belo Horizonte, UFMG, 2008 (Tese de doutoramento).

NIETZSCHE, Friedrich. Sämtliche Werke. Kritische Studienausgabe (KSA: 15 vols.). Hrsg. von G. Colli und M. Montinari. Berlin/New York: de Gruyter, 1988. 
- Werke und Briefe. Historisch-Kritische Gesamtausgabe (BAW: 05 vols.). Hrsg. von Hans Joachim Mette und Karl Schlechta. München: C. H. Beck'sche Verlagsbuchhandlung (1933-1940), 1994.

. Obras Incompletas. In: Col. Os pensadores. Trad. Rubens R. T. Filho. São Paulo: Abril Cultural, 1983.

PERELMAN, C. Retóricas. Trad. Maria E. G. G. Pereira. São Paulo: Martins Fontes, 1997.

SALAQUARDA, J. "Studien zur Zweiten Unzeitgemäßen Betrachtung“. In: Nietzsche-Studien, 12, 1984: p. 1-45.

SKINNER, Q. "Meaning and understanding in the history of ideas". In: TULLY, J. (Org.). Meaning and context: Quentin Skinner and his critics. Princeton: Princeton University Press, 1988.

SOMMER, A. Urs. "Vom Nutzen und Nachteil kritischer Quellenforschung: Einige Überlegungen zum Fall Nietzsches”. In: Nietzsche-Studien, 29, 2000: p. 302-316.

STRAUSS, L. Persecution and the art of Writing. Chicago/London: The University of Chicago Press, 1988. 